\title{
Bilateral TMJ ankylosis, anesthetic and surgical challenge- case report
}

\author{
Vanza B ${ }^{1}$, Patel $\mathbf{U}^{2}$, Kulkarni ${ }^{3}$, Khare $\mathrm{N}^{4}$ \\ ${ }^{1}$ Dr. Bhavuk Vanza, Assistant Professor (Oral \& Maxillofacial Surgery), Rishiraj Dental College, Bhopal (MP), ${ }^{2}$ Dr. \\ Umesh Patel, Associate Professor (Pediatrics), LN Medical College, Bhopal (MP), ${ }^{3}$ Dr. Kulkarni, Associate Professor \\ (ENT), LN Medical College, Bhopal (MP), ${ }^{4}$ Dr. Neha Khare, Assistant Professor (Periodontics), RKDF Dental College, \\ Bhopal (MP)
}

Address for Correspondence- Dr. Bhavuk Vanza, raj_vanza@rediffmail.com

\begin{abstract}
Bilateral Temporomandibular Joints ankylosis brings extensive limitations on the patient quality of life. Surgical treatment is frequently necessary associated with a continuous rehabilitation. To avoid iatrogenic injuries and potential complications, anatomy of this region, must be thoroughly known by operating surgeon.
\end{abstract}

Key words: Temperomandibular Joints, Ankylosis, Temporalis myofacial grafting.

\section{Introduction}

Ankylosis of temporomandibular joint (TMJ) is an intracapsular union of the disc-condyle complex to temporal articular surface that restricts mandibular movement, including the fibrous adhesions or bony fusion between condyle, disc, glenoid fossa, and articular eminence [1]. Mandibular Hypomobiliy results from a variety of disorders affecting TMJ and surrounding structures. TMJ ankylosis is more commonly associated with trauma (13-100\%), local or systemic infection $(10-49 \%)$, or systemic diseases $(100 \%)$, such as ankylosing spondylitis, rheumatoid arthritis, and psoriasis. However, it can also occur as a result of TMJ surgery, congenitally or secondary to severe rheumatoid arthritis or to tumors in the area of TMJ [2]. It is generally classified on the basis of location, type of tissue involved and extent of its fusion [3]. TMJ ankylosis in the pediatric patient often leads to facial deformities, difficulty in chewing and swallowing, speech problem, poor oral hygiene [4]. Facial asymmetry develops if only one side is affected. Disturbances of facial and mandibular growth and acute compromise of the airway invariably result in physical and psychological disability [5]. Severity of ankylosis is diagnosed clinically by evaluating the degree to which mouth opening is restricted. X-rays, CT scans, or MRI tests determine the abnormality in the bony or soft tissue formations in the joint [6]. The treatment of TMJ

Manuscript received: $22^{\text {nd }}$ Feb 2016

Reviewed: $6^{\text {th }}$ March 2016

Author Corrected; $18^{\text {th }}$ March 2016

Accepted for Publication: $31^{\text {st }}$ March 2016 ankylosis is challenging, because of technical difficulties, frequeny complications and high incidence of recurrence [7]. Team approach is required for resolving functional, cosmetic, psychological or social problems associated with ankylosis. The arthroplasty results not only in adequate mouth opening but also reestablish jaw movements in the TMJ ankylosis patients. Important consideration in the management of this condition is to restore the dental occlusion along with the prevention of re-ankylosis during subsequent time.

\section{Case Report}

15 years old male patient, reported to the clinic of oral and maxillofacial surgery, with chief complaint of inability to open mouth since the age of 2 years. Patient had left ear infection at the age of 1.5 years after which parents noticed reduction and painful mouth opening with complete cessation of jaw activity at the age of 2 years. Clinically patient had straight mentohyoid angle and facial fullness on right side. There was accentuation of antegonial notch on right side. Radiological evaluation determined that there was Nelson's grade II ankylosis on left side where as grade III ankylosis with involvement of coronoid on the right side. Patient was screened for any other developmental or acquired anomalies, after which he was prepared for surgery. Fiberoptic nasal intubation was considered, but could not lead to satisfactory intubation, therefore tracheostomy was performed. Bilateral Temporalis Interpositioning grafts was placed after excision of 
ankylotic mass to achieve $4 \mathrm{~cm}$ of intra operative mouth opening. Bilaterally minivac drains were secured and closure was commenced. Active physiotherapy was commenced at $5^{\text {th }}$ post op day and tracheostomy was removed uneventfully on $12^{\text {th }}$ post op day. Patient is kept under follow up as his mandibular anatomy is

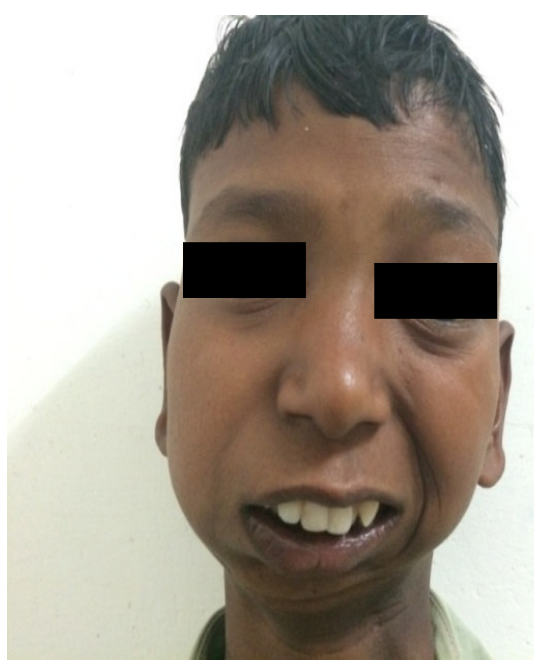

Fig 1: Before surgery not able to open mouth severely distorted along with severe canting of maxilla on left side. On every post op follow up, Orthopentamograph (OPG) x-ray shall be taken to monitor the development pattern and signs of recurrence of the disease.

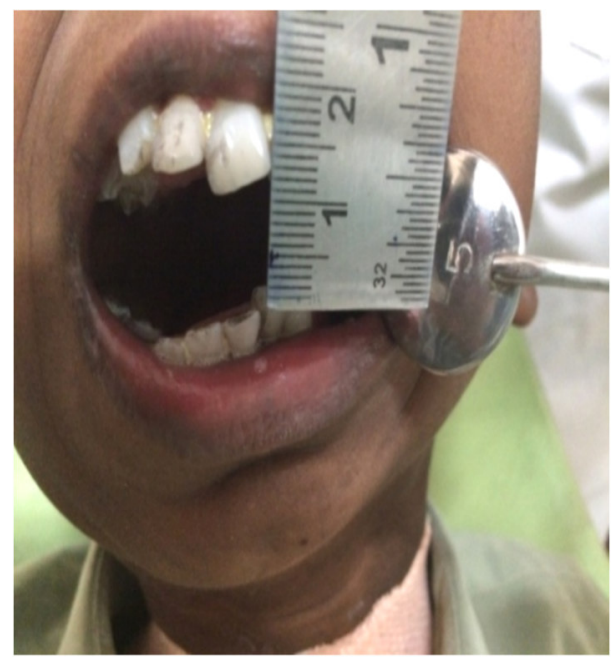

Fig 2: more than $1 \mathrm{~cm}$ opening after surgery

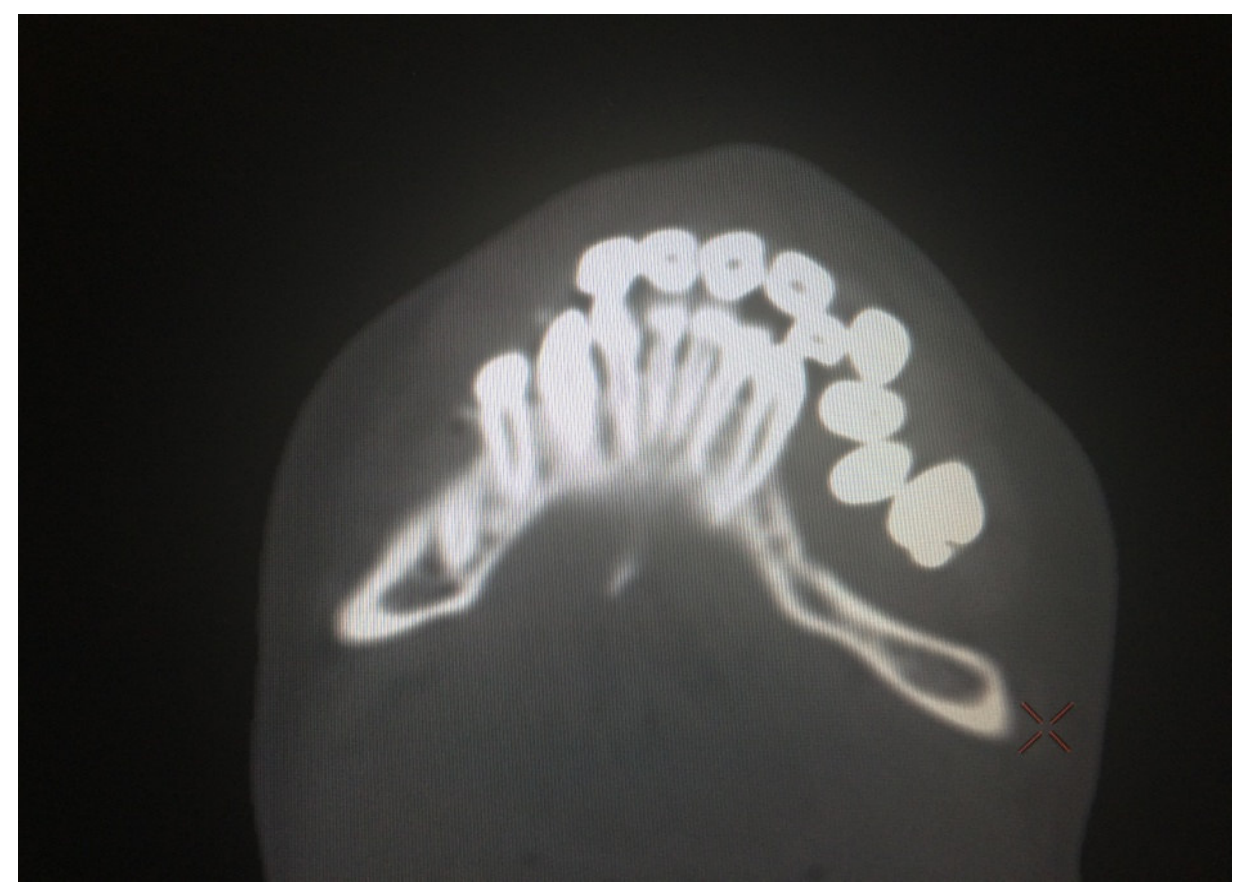

Fig 3: X ray suggestive of Ankylosis with bony deformity 


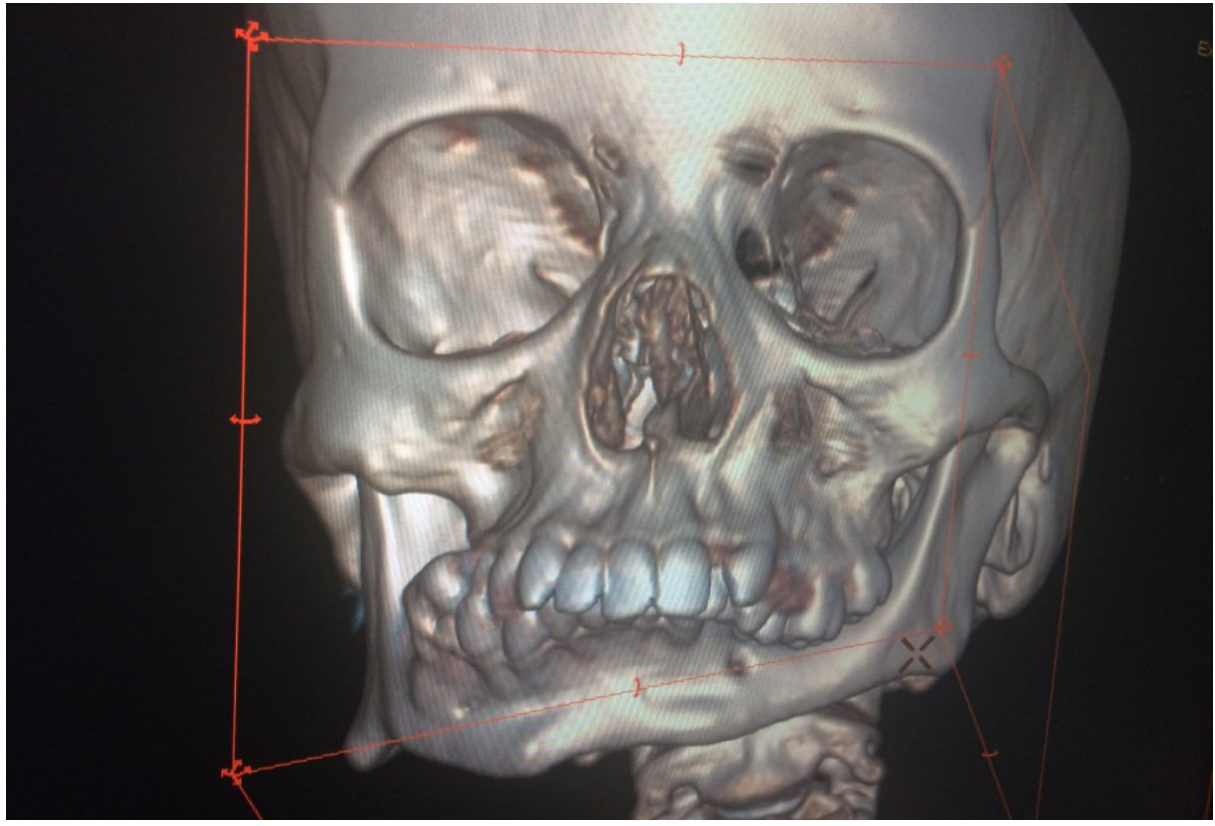

Fig 4: showing ankylosis with bony and dental deformity.

\section{Discussion}

Untreated TMJ ankylosis in children results in significant adverse consequences. Facial asymmetry progressive worsens because of the hypo-mobility and abnormal muscle function. Longer the duration of hypomobility, the more severe will be the muscle atrophy and facial asymmetry. In addition, secondary elongation and hypertrophy of the coronoid process occurs, further restricting jaw motion. The prognosis for a favorable outcome with treatment is inversely related to the number of years of ankylosis. Therefore treatment of ankylosis should be done as soon as it is feasible to expect patient co-operation. Usually children more than the age of 3 years are candidates of ankylosis release. Most frequently reported operation include gap arthroplasty, interpositional arthroplasty, excision and joint reconstruction with autogenous or alloplastic material. The choice of surgery depends upon various factors, including age, medical status, growth potential, reccurence potential, possibilities of grafting and

\section{Reference}

1. Long X, Li X, Cheng Y, Yang X, Qin L, Qiao Y, Deng $M$. Preservation of disc for treatment of traumatic temporomandibular joint ankylosis. J Oral Maxillofac Surg. 2005 Jul;63(7):897-902. advantages and disadvantanges of various interpositional and reconstructive materials [8]. In patients treated with gap arthroplasty average increase in mouth opening was $32 \mathrm{~mm}$, and the results were considered satisfactory. In our case, mouth opening intra operatively was $4.2 \mathrm{~cm}$ and passive mouth opening 12 th day post operative was measured to be $1.5 \mathrm{~cm}$. Patient is advised active physiotherapy for 8 months with regular monthly follow up. Post operative OPG will be done to evaluate the progress [9].

\section{Conclusion}

Multidisciplinary team approach is required for better outcome for treatment of bilateral TMJ ankylosis. Long term follow up with active physiotherapy can ascertain good and uneventful healing and ultimately success of the treatment.

Funding: No Funding

Conflict of Interest: The authors declare no conflict of Interes.

2. He D, Yang C, Chen M, Zhang X, Qiu Y, Yang X, Li L, Fang B. Traumatic temporomandibular joint ankylosis: our classification and treatment experience. J Oral Maxillofac Surg. 2011 Jun;69(6):1600-7. doi: 10.1016/j.joms.2010.07.070. Epub 2011 Feb 5. 
3. Rowe NL. Ankylosis of the temporomandibular joint. J R Coll Surg Edinb. 1982 Mar;27(2):67-79.

4. Kaban LB, Bouchard C, Troulis MJ. A protocol for management of temporomandibular joint ankylosis in children. J Oral Maxillofac Surg. 2009 Sep;67(9):1966-78. doi: 10.1016/j.joms.2009.03.071.

5. Vibhute PKJ, Bhola N, Rajiv M. Borle. "TMJ Ankylosis: Multidisciplinary Approach of Treatment for Dentofacial Enhancement-A Case Report". Case Reports in Dentistry.2011; 2011: 7 pages.

6. Kaban LB, Bertolami CN. The role of CT scan in diagnosis of TMJ ankylosis: report of case. J Oral Surg. 1981 May;39(5):370-2.
7. Loveless TP, Bjornland T, Dodson TB, Keith DA. Efficacy of temporomandibular joint ankylosis surgical treatment. J Oral Maxillofac Surg. 2010 Jun;68(6):1276-82. doi: 10.1016/j.joms.2009.10.014. Epub 2010 Mar 20.

8. Chossegros C, Guyot L, Cheynet F, Blanc JL, Cannoni P. Full-thickness skin graft interposition after temporomandibular joint ankylosis surgery. A study of 31 cases. Int J Oral Maxillofac Surg. 1999 Oct;28(5):330-4.

9. Danda AK, S R, Chinnaswami R. Comparison of gap arthroplasty with and without a temporalis muscle flap for the treatment of ankylosis. J Oral Maxillofac Surg. 2009 Jul;67(7):1425-31. doi: 10.1016/j.joms.2008.12.049.

\section{How to cite this article?}

Vanza B, Patel U, Kulkarni, Khare N, Bilateral TMJ ankylosis, anesthetic and surgical challenge- case report. Pediatr rev. Int J Pediatr Res 2016;3(3):202-205. doi:10.17511/ijpr.2016.i03.12. 